\title{
Determination of Sulfur in Fossil Fuels by Isotope Dilution Thermal Ionization Mass Spectrometry
}

\author{
W. Robert Kelly, "† Paul J. Paulsen, ${ }^{\dagger}$ Karen E. Murphy, ${ }^{\dagger}$ Robert D. Vocke, Jr., ${ }^{\dagger}$ and Le-Tlan Chen ${ }^{\dagger, \ddagger}$ \\ Chemical Science and Technology Laboratory, National Institute of Standards and Technology, \\ U.S. Department of Commerce, Gaithersburg, Maryland 20899
}

Total sulfur has been measured in 13 petroleum and 14 coal Standard Reference Materials (SRMs) by isotope dilution thermal ionization mass spectrometry. These materials are suitable as primary and quality control standards for determining the sulfur content of oils and coals by $X$-ray fluorescence and high-temperature combustion instrumentation. Samples were spiked with enriched stable ${ }^{34} \mathrm{~S}$ and combusted in sealed Carius tubes using nitric and hydrochloric acids. The oxidized sulfur was reduced to $\mathrm{H}_{2} \mathrm{~S}$, precipitated as $A s_{2} \mathrm{~S}_{3}$, and then dissolved in an ammoniacal solution of $\mathrm{As}_{2} \mathrm{O}_{3}$. A portion of this solution, equivalent to $1.5 \mu \mathrm{g}$ of sulfur, was added to a single Re filament coated with silica gel. The amount of sulfur in the samples was determined from the ${ }^{32} \mathrm{~S} /{ }^{34} \mathrm{~S}$ ratio by measuring the ${ }^{75} \mathrm{As}^{32} \mathrm{~S}^{+} /{ }^{75} \mathrm{As}^{34} \mathrm{~S}^{+}$molecular ions in a Faraday detector. A total of 158 sulfur procedural blanks covering a 10-year period show an approximate log-normal distribution with a grand mean of $0.26 \mu \mathrm{g}$ of sulfur. This is a negligible correction for most of the data reported here. The total uncertainty (95\% confidence interval) for homogeneous materials such as oils is about $\mathbf{0 . 5 \%}$, and for less homogeneous materials such as coals is $1-4 \%$.

One of the most important properties of fossil fuels is their sulfur content. Combustion of fossil fuels is the primary source of anthropogenic sulfur compounds released into the atmosphere. Recent estimates suggest that the anthropogenic flux into the atmosphere may be equal to or greater than the natural flux. Electric utilities within the United States burn a large amount of fossil fuel and are responsible for approximately $70 \%$ of the $\mathrm{SO}_{2}$ emitted into the atmosphere. ${ }^{1}$ After entering the atmosphere, oxides of sulfur are converted to sulfuric acid and sulfate particles. These particles play an important role in the physics and chemistry of the atmosphere. The radiation budget of the earth is influenced by the fine particles in the atmosphere. Visibility degradation resulting from sulfate aerosols has been of concern particularly in pristine areas such as national parks. Rollback in sulfur emissions from fossil-fueled power plants has been an environmental goal for the last two decades.

The accurate determination of the concentration of sulfur in fossil fuels is important for several reasons. The quality and price of both petroleum and coal are related to the amount of sulfur present. There are federal, state, and local regulations

\footnotetext{
U.S. Department of Commerce.

t Permanent address: Research Center for Eco-Environmental Sciences, Academia Sinica, P.O. Box 2871, Beijing, China 100085

(1) (a) Galloway, J. N.; Whelpdale, D. M. Atmos. Environ. 1980, 14, 409. (b) Ember, L. Chem. Eng. News 1991, 69, 20.
}

that limit the amount of sulfur oxides that can be emitted during the combustion of fossil fuels. Electric power companies must monitor the emissions from their stacks in order to comply with regulations of the Environmental Protection Agency. These companies also closely monitor the sulfur content of their incoming feedstocks to ascertain the quality, acceptability, and price. The fossil fuel producers and users require fast and inexpensive methods for the determination of sulfur in the range of $1-5 \%$ sulfur. Accurate determinations covering this range are needed because both producers and users must frequently blend fuels to meet several chemical and physical specifications simultaneously. Compliance coal emits $1.2 \mathrm{lb}$ of $\mathrm{SO}_{2}$ per $10^{6} \mathrm{Btu}$, which is equivalent to approximately $0.7 \%$ sulfur. ${ }^{2}$ The exact amount of $\mathrm{SO}_{2}$ that can be legally emitted from a source burning oil or coal depends on a number of factors including the age of the plant and its geographical location.

As of October 1, 1993, new EPA regulations require that refiners reduce the sulfur content of on-highway diesel fuel from present levels of approximately $0.25 \%$ to less than $0.05 \% .^{3}$ Low sulfur content of diesel fuel will enable engine manufacturers to use after-treatment technology to reduce particulate emissions to meet standards which go into effect in $1994 .^{4}$

The accurate determination of sulfur at these levels on a routine basis represents a significant measurement challenge for the industry. The two most common techniques employed for the determination of sulfur are X-ray fluorescence and high-temperature combustion followed by infrared detection or iodimetric titration of the liberated $\mathrm{SO}_{2}$. These instruments can determine the sulfur content at the $1 \%$ level with an uncertainty, $95 \%$ confidence interval $(95 \% \mathrm{CI})$, of approximately $1 \%$ relative. In recent years ion chromatography (IC) with conductimetric detection has also been used. The first two methods require external standards and may be subject to instrumental or sample preparation biases. Matrix matching of samples and standards is required for accurate measurement. In X-ray fluorescence, the ratio of $\mathrm{C}, \mathrm{H}$, and $O$ to sulfur in the sample can affect the accuracy of the sulfur determination. IC is a highly sensitive technique for sulfur, but the sample preparation step is critical. Complete combustion of the sample is required, followed by dilution in an aqueous medium before the determination. Loss of sulfur at any stage of the preparation process will produce a negative

(2) Kerch, R. L. J. Air Waste Manage. Assoc. 1985, 35, 213.

(3) Fed. Regist. 1990, 55, 34120

(4) Fed. Regist. 1990, 55, 34137. 
bias in the final result. Therefore, for accurate sulfur determinations, these instruments must be calibrated with standards that have been accurately certified.

The producers and users of fossil fuels use analytical techniques that have been approved by the American Society for Testing and Materials (ASTM). Indeed, the sulfur content is legally defined by an ASTM standard test method. ${ }^{5}$ The petroleum industry commonly uses $\mathrm{X}$-ray fluorescence ${ }^{6}$ or high-temperature combustion. ${ }^{7}$ The coal industry uses a hightemperature combustion method $^{7}$ and less frequently gravimetry ${ }^{8}$ but usually does not use X-ray fluorescence because of the inherent heterogeneity of coal. All of the techniques employed in these test methods require standards for calibration. Uncorrected biases in sulfur determinations can lead to significant differences among laboratories. If companies burn fossil fuels that are not in compliance with EPA regulations, then they may be subject to large fines.

There is a need for Standard Reference Materials (SRMs) certified accurately for sulfur content and with small uncertainties. Ideally, one desires to calibrate an instrument with a standard that has an uncertainty that is considerably less than the accuracy of the technique being used. There is also a very important practical reason for small uncertainties in the standards used for calibration. The uncertainties in the standards are normally not propagated into the calibration curves by the user. The inherent assumption is that there is no uncertainty in the standard. Although this assumption has practical utility, it may cause real problems if the standard is heterogeneous or if several different standards are used for calibration curves. If two different laboratories use different standards, they may measure what appears to be a real difference in a test sample when the difference may not be significant if the uncertainties in the calibration curves had been propagated properly. There also may be biases in calibration curves if one or more of the standards used for calibration were not certified accurately. A detailed discussion of this type of problem has been published recently. 9,10

In 1981, the mass spectrometry group of the Inorganic Analytical Research Division initiated the development of an isotope dilution technique for the determination of sulfur. This was in response to a report that suggested certified values in some steel SRMs were possibly too high by as much as $20 \%$ and to fulfill a need for an accurate technique for the determination of sulfur in Standard Reference Materials. Isotope dilution is considered an accurate technique by the Standard Reference Materials Program (SRMP). Its inherent accuracy and high precision have long been recognized in the physical science community. An accurate technique is one in which the sources of random and systematic error have been

(5) ASTM D 2622-87 Standard Test Method for Sulfur in Petroleum Products by X-Ray Spectrometry. Annu. Book ASTM Stand. 1990, 05.02, 322.

(6) (a) ASTM D 4294-83 Standard Test Method for Sulfur in Petroleum Products by Non-Dispersive X-Ray Fluorescence Spectrometry. Annu. Book ASTM Stand. 1990, 05.03, 349. (b) ASTM D 4239-85 Standard Test Methods for Sulfur in the Analysis Sample of Coal and Coke Using High Temperature Tube Furnace Combustion Methods. Annu. Book ASTM Stand. 1990, 05.05 374.

(7) ASTM D 1522-88 Standard Test Methods for Sulfur in Petroleum Products (High-Temperature Method). Annu. Book ASTM Stand. 1988, 05.01, 606

(8) ASTM D 3177-89 Standard Test Methods for Total Sulfur in the Analysis Sample of Coal and Coke. Annu. Book ASTM Stand. 1990, 05.05, 319.

(9) MacDonald, B. S. J. Coal Qual. 1988, 7, 135.

(10) Kelly, W. R.; Murphy, K. E.; Paulsen, P. J. to be submitted to J. Coal Qual. evaluated, the proper corrections have been made to the measured data, and all sources of uncertainty assessed and clearly stated. ${ }^{11}$ One of the first descriptions of inorganic isotope dilution by mass spectrometry was in an ASTM special publication in 1951.12 Isotope dilution analysis is based upon the chemical equilibration of a known amount of an enriched isotope with the isotopes of the element being determined and the measurement of the isotopic ratio of the resulting mixture. It is inherently accurate because after the spike is mixed with the sulfur in the sample, only an isotopic ratio needs to be measured, and the ratios can be measured with high accuracy and precision. Quantitative recovery of the sample is not required for accuracy. Sulfur has four stable isotopes with the following nominal abundances: ${ }^{32} \mathrm{~S}, 95 \% ;{ }^{33} \mathrm{~S}, 0.75 \% ;{ }^{34} \mathrm{~S}$, $4.2 \%$; and ${ }^{36} \mathrm{~S}, 0.02 \%$. Using sulfur enriched in ${ }^{34} \mathrm{~S}$ as the tracer, the most accurate data are obtained by measuring the ${ }^{32} \mathrm{~S} /{ }^{34} \mathrm{~S}$ ratio. The inherent accuracy of the technique is readily apparent from the following considerations. The measured ratio in the mixture $(\mathrm{m})$ is given by the atom balance relation:

$$
\left[\frac{{ }^{32} S}{{ }^{34} \mathrm{~S}}\right]_{\mathrm{m}}=\frac{\left({ }^{32} \mathrm{~S}\right)_{\mathrm{s}}+\left({ }^{32} \mathrm{~S}\right)_{\mathrm{t}}}{\left({ }^{34} \mathrm{~S}\right)_{\mathrm{s}}+\left({ }^{34} \mathrm{~S}\right)_{\mathrm{t}}}
$$

where the numerator and denominator equal the sum of the moles of ${ }^{32} \mathrm{~S}$ and ${ }^{34} \mathrm{~S}$, respectively, in the sample (s) and the spike ( $t$ ). Equation 1 can be arranged to give the following:

$$
\left({ }^{32} S\right)_{s}=\left({ }^{34} S\right)_{t} \frac{\left(\frac{{ }_{t} S}{{ }^{34} S}\right)_{t}-\left(\frac{{ }^{32} S}{{ }^{34} S}\right)_{m}}{\left(\frac{{ }^{32} S}{{ }^{34} S}\right)_{m}\left(\frac{{ }^{34} S}{{ }^{32} S}\right)_{s}-1}
$$

It is obvious from eq 2 that to determine the number of moles of ${ }^{32} \mathrm{~S}$ in the sample, only isotopic ratios need to be measured, assuming that the amount of tracer $\left[\left({ }^{34} \mathrm{~S}\right)_{\mathrm{t}}\right]$ added is known. Therefore, the accuracy of an isotope dilution determination is independent of chemical yields provided blanks are relatively small. ${ }^{13}$ The concentration of sulfur in a sample is given by the following relation:

$$
C_{\mathrm{s}}=\frac{\left({ }^{32} \mathrm{~S}\right)_{\mathrm{s}}(\text { at. wt })}{\left({ }^{32} \mathrm{~A}\right)(\mathrm{wt})} \times 10^{6} \mu \mathrm{g} \mathrm{g}^{-1}
$$

where the numerator equals the product of the moles of ${ }^{32} \mathrm{~S}$ and the atomic weight of sulfur in the sample and the denominator equals the product of the fractional abundance of ${ }^{32} \mathrm{~S}$ in the sample and the sample weight in grams.

An isotope dilution-spark source mass spectrometric (IDSSMS) procedure for the determination of sulfur was developed in $1981 .^{14}$ The ID-SSMS technique had an uncertainty of about $2 \%(95 \% \mathrm{CI})$. In this procedure,

(11) Moody, J. R.; Epstein, M. S. Spectrochim. Acta 1991, 46B, 1571.

(12) Inghram, M. G. In Symposium on Chemical Analysis of Inorganic Solids by Means of the Mass Spectrometer; Special Technical Publication No. 149; American Society for Testing Materials: Philadelphia, 1951; pp 1-9.

(13) Kelly, W. R.; Hotes, S. A. J. Res. Natl. Bur. Stand. 1988, 93, 228.

(14) (a) Paulsen, P. J.; Burke, R. W.; Maienthal, E. J.; Lambert, G. M. ASTM STP 747; Javeir-Son, A., Ed., American Society for Testing and Materials: Philadelphia, PA, 1981; p 113 . (b) Burke, R. W.; Paulsen, P. J.; Maienthal, E. J.; Lambert, G. M. Talanta 1982, 29, 809. 
samples were spiked with highly enriched ${ }^{34} \mathrm{~S}$ and equilibrated in a Carius tube at high temperature and pressure. The Carius tube is a glass tube that is heat sealed and, thus, is a completely closed system. The resulting isotopic mixture, after chemical processing, was measured as the $\mathrm{S}^{+}$ion in a spark source mass spectrometer. The procedure was applicable to all types of materials and was used for the determination of sulfur concentrations from a few micrograms per gram to several percent. The results of these measurements demonstrated that low sulfur values obtained in other work resulted from the loss of sulfur from open beakers during the dissolution step. Moreover, in a limited survey of ferrous metals with low sulfur content, one sample (SRM 342a, nodular cast iron) that had been certified for sulfur in 1970 at $60 \mu \mathrm{g} \mathrm{g}^{-1}$ was found to have a concentration of $23 \pm 2 \mu \mathrm{g} \mathrm{g}^{-1}(95 \% \mathrm{CI})$. This finding raised the possibility that steels certified to contain sulfur concentrations below $100 \mu \mathrm{g} \mathrm{g}^{-1}$ may be in error. More generally, it pointed to the danger of employing techniques operating near their limit of detection and also suggested that gravimetry may be subject to large errors. After the development of the spark source technique, a different procedure was explored based on isotope dilution-thermal ionization mass spectrometry (ID-TIMS), which was first reported in this journal in $1984 .{ }^{15}$ In this procedure, the sulfur is measured as the $\mathrm{AsS}^{+}$molecular ion at the relatively low temperature of $950^{\circ} \mathrm{C}$. Since As is mononuclidic with a mass of 75 , the measured ${ }^{75} \mathrm{As}^{32} \mathrm{~S}^{+} /{ }^{75} \mathrm{As}^{34} \mathrm{~S}^{+}$ratio yields the measured ${ }^{32} \mathrm{~S} /{ }^{34} \mathrm{~S}$ ratio directly without any corrections to the ion currents. Thermal ionization mass spectrometry is about a factor of 10 more accurate than SSMS. This procedure also uses the Carius tube technique for dissolution of the sample and essentially the same chemical procedure as the ID-SSMS procedure. This is the first comprehensive paper on the use of this technique for the determination of sulfur in fossil fuels.

\section{EXPERIMENTAL SECTION}

The experimental details have been published previously; ${ }^{15-19}$ therefore, only a brief description is given here.

Chemical Procedure. NIST high-purity subboiling distilled acids were used for the combustion of all samples. For the oil samples, $3 \mathrm{~mL}$ of oil was drawn into a Fortuna $5 \cdot \mathrm{mL}$ plastic syringe fitted with a plastic cap. Approximately $0.2-0.3 \mathrm{~g}$ of oil was added to the Carius tubes using the plastic syringe. In the case of coal samples, approximately $0.15 \mathrm{~g}$ of coal was added using a glass funnel in the shape of a boat that could be weighed. Separate samples were dried at $105^{\circ} \mathrm{C}$ for $2 \mathrm{~h}$, and a weight correction was applied to the samples. Highly enriched ${ }^{34} \mathrm{~S}$ spike was then added with a plastic syringe so that the mixture would yield a ${ }^{32} \mathrm{~S} /{ }^{34} \mathrm{~S}$ ratio of about $2-3$. Oil samples were combusted using $10 \mathrm{~g}$ of NIST $\mathrm{HNO}_{3}$ and $2 \mathrm{~g}$ of NIST $\mathrm{HCl}$. In some cases, only $\mathrm{HNO}_{3}$ was used. Coal samples were combusted using $8 \mathrm{~g}$ of NIST $\mathrm{HNO}_{3}$. After the addition of the sample, spike, and acids, the Carius tubes were

(15) Paulsen, P. J.; Kelly, W. R. Anal. Chem. 1984, 56, 708.

(16) Kelly, W. R.; Paulsen, P. J. Talanta 1984, 31, 1063.

(17) Kelly, W. R.; Chen L.-T.; Gramlich, J. W.; Hehn, K. A. Analyst 1990, 115 1019 .

(18) Kelly, W. R.; Murphy, K. E. Geostand. Newsl. 1992, 16, 3.

(19) Kelly, W. R.; Paulsen, P. J. In Methods and Procedures used at the National Bureau of Standards to Certify Sulfur in Coal SRMs for Sulfur Content. Calorific Value, Ash Content; Gills, T. E., Ed.; Special Publication 260-94; National Bureau of Standards: Washington, DC, 1984; pp 7-13. frozen in a solid $\mathrm{CO}_{2}-\mathrm{CHCl}_{3}-\mathrm{CCl}_{4}$ mixture and then sealed with an oxygen-natural gas torch. The sealed tubes were put in steel shells and placed in a laboratory oven. All samples were heated at $50{ }^{\circ} \mathrm{C}$ increments to $240{ }^{\circ} \mathrm{C}$, and this temperature was maintained for $12-15 \mathrm{~h}$. The pressure inside the tube at this temperature is about $10 \mathrm{MPa}(\sim 100 \mathrm{~atm})$. After this treatment, all sulfur species are oxidized to the sulfate form, and the hydrocarbon matrix is completely combusted as represented in the following relation:

$$
\left[\mathrm{CH}_{2}\right]+6 \mathrm{HNO}_{3} \rightarrow \mathrm{CO}_{2}+6 \mathrm{NO}_{2}+4 \mathrm{H}_{2} \mathrm{O}
$$

The Carius tube combustion is a truly closed system and is one of the few techniques that is capable of complete wet oxidation of organic matter.

After cooling to room temperature, the tube is opened, and the contents are converted to the chloride form. The sample is then reduced to $\mathrm{H}_{2} \mathrm{~S}$, which is trapped in $1 \mathrm{~mL}$ of aqueous ammonia containing As as dissolved $\mathrm{As}_{2} \mathrm{O}_{3}$ at a concentration of $1000 \mu \mathrm{g} \mathrm{mL}^{-1}$. The sulfur is precipitated as $\mathrm{As}_{2} \mathrm{~S}_{3}$ by the dropwise addition of concentrated hydrochloric acid, and the precipitate is washed with distilled water. The precipitate is then dissolved in aqueous ammonia containing As such that the final concentration of sulfur is $100 \mu \mathrm{g} \mathrm{mL}^{-1}$ and the As/S atomic ratio is 2 .

Mass Spectrometry. A small portion of the above solution containing about $1.5 \mu \mathrm{g}$ of sulfur is loaded onto a Re filament using silica gel as an emitter. The ${ }^{32} \mathrm{~S} /{ }^{34} \mathrm{~S}$ ratio in the sample is determined by measuring the ${ }^{75} \mathrm{As}^{32} \mathrm{~S}^{+} /{ }^{75} \mathrm{As}^{34} \mathrm{~S}^{+}$molecular ion ratio in a $30-\mathrm{cm} 90^{\circ}$ sector NIST thermal ionization mass spectrometer. In a spiked sample with a ${ }^{32} \mathrm{~S} /{ }^{34} \mathrm{~S}$ ratio of approximately unity, the repeatability of the ratio measurement is typically $0.05 \%$ within a run. The fundamental limitation to accuracy resulting from the variability in fractionation between runs is about $0.2 \%$.

The sulfur isotopic composition is variable in nature as a result of mass fractionation during biological processing of sulfur. Therefore, the isotopic composition of each sample is measured on an unspiked sample in order to calculate the four atomic abundances and the atomic weight of sulfur for that sample.

Calibration of Spike. The enriched ${ }^{34} \mathrm{~S}$ tracer was calibrated against high-purity $\mathrm{K}_{2} \mathrm{SO}_{4}$ and $\mathrm{Na}_{2} \mathrm{SO}_{4}$ and against coulometrically titrated NIST high-purity $\mathrm{H}_{2} \mathrm{SO}_{4}$. The calibration of the spike is the reverse of measuring a sample. In this case, the left-hand side of eq 2 is known, and the factor $\left({ }^{34} \mathrm{~S}\right)_{t}$ is determined. The calibration of the spike has been discussed in detail. ${ }^{17}$

Safety Considerations. The dangers associated with the use of Carius tubes and hypophosphorous acid were discussed in our first paper. ${ }^{15}$ This paper and references therein must be understood before undertaking this procedure.

\section{RESULTS AND DISCUSSION}

There are several biases or fixed errors that can affect the accuracy of the sulfur measurements. These are discussed below.

Isotopic Composition of Sulfur. The sulfur compositions measured in the fossil fuel standards are shown in Table 1 and show a $2.8 \%$ spread in the ${ }^{32} \mathrm{~S} /{ }^{34} \mathrm{~S}$ ratios. If values from the 


\begin{tabular}{cccc}
\hline $\begin{array}{c}\text { Table 1. } \\
\text { SRM }\end{array}$ & $\begin{array}{c}\text { Natural Isotoplc } \\
\left(32 \mathrm{~S} /{ }^{34} \mathrm{~S}\right)^{b}\end{array}$ & $\begin{array}{c}\text { Compostion of SRMsa } \\
\left({ }^{33} \mathrm{~S} /{ }^{34} \mathrm{~S}\right)^{c}\end{array}$ & $\left({ }^{\mathrm{c}} \mathrm{S} /{ }^{34} \mathrm{~S}\right)^{d}$ \\
1617 & 22.714 & 0.1788 & 0.00355 \\
$1619 \mathrm{a}$ & 22.640 & 0.1784 & $0.0036^{e}$ \\
$1620 \mathrm{~b}$ & 22.930 & 0.1795 & $0.036^{e}$ \\
$1621 \mathrm{c}$ & 22.710 & 0.1790 & $0.0036^{e}$ \\
$1621 \mathrm{~d}$ & 22.574 & 0.1776 & $0.0036^{e}$ \\
$1622 \mathrm{c}$ & 22.854 & 0.1802 & $0.0036^{e}$ \\
$1622 \mathrm{~d}$ & 22.814 & 0.1790 & $0.0036^{e}$ \\
$1623 \mathrm{~b}$ & 22.560 & 0.1783 & $0.0036^{e}$ \\
$1624 \mathrm{a}$ & 22.583 & 0.1782 & 0.00343 \\
$1624 \mathrm{~b}$ & 22.598 & 0.1790 & 0.00427 \\
$1624 \mathrm{~b}$ & 22.624 & 0.1784 & 0.00342 \\
$1632 \mathrm{~b}$ & 22.377 & 0.1774 & $0.0036^{e}$ \\
1635 & 22.546 & 0.1778 & $0.0036^{e}$ \\
2692 & 22.584 & 0.1782 & 0.00337 \\
2682 & 22.699 & 0.1783 & $0.0036^{e}$ \\
$2682 \mathrm{a}$ & 22.831 & 0.1792 & $0.0036^{e}$ \\
2683 & 22.364 & 0.1769 & $0.0036^{e}$ \\
$2683 \mathrm{a}$ & 22.352 & 0.1776 & 0.00344 \\
$2683 \mathrm{a}$ & 22.347 & 0.1772 & $0.0036^{e}$ \\
2684 & 22.726 & 0.1782 & $0.0036^{e}$ \\
$2684 \mathrm{a}$ & 22.680 & 0.1777 & 0.00351 \\
$2684 \mathrm{a}$ & 22.689 & 0.1785 & $0.0036^{e}$ \\
2685 & 22.546 & 0.1777 & $0.0036^{e}$ \\
$2685 \mathrm{a}$ & 22.565 & 0.1782 & $0.0036^{e}$ \\
2717 & 22.995 & 0.1806 & $0.0036^{e}$ \\
2724 & 22.667 & 0.1783 & $0.0036^{e}$
\end{tabular}

a The isotopic ratios are not absolute values; they differ from the absolute value by an unknown mass fractionation factor. ${ }^{b}$ The uncertainty is estimated to be $0.2 \%$ relative. $c$ The uncertainty is estimated to be $0.5 \%$ relative. $d$ The uncertainty is estimated to be $5 \%$ relative. "This ratio was not measured. The ${ }^{36} \mathrm{~S}$ abundance was assumed to be $0.015 \%$.

chart of the nuclides were used in all calculations, this could result in a $1 \%$ bias in the worse case. In this study, the measured quantities are used in the calculation of the sulfur concentration. Although these measured abundances differ from the true values by an unknown mass fractionation factor, it is straightforward to show that this effect cancels if the samples and spike calibration are measured under identical conditions.

Isotopic Composition of Sulfur Spike. In eq 2, the first term in the numerator is the composition of the spike. The true composition of the spike must be known or a small bias may result. The magnitude of the bias depends on the purity of the spike and the amount of spike added to the sample. If the spike is calibrated with a measured ${ }^{32} \mathrm{~S} /{ }^{34} \mathrm{~S}$ ratio, $R_{1}$, and the unknown samples are spiked such that the measured ratio is $R_{2}$, which is the usual case, then the bias is zero only for $R_{1}=R_{2}$. However, if the calibration of the spike and the determination of the samples are measured such that $R_{1} \neq$ $R_{2}$, then a small bias may result.

The composition of the spike is normally determined by adding a small portion of the spike directly to a filament, sufficient to overwhelm the natural background in the filament, and the composition measured directly. In the sulfur procedure, however, this is not possible since the oxidized sulfur must be passed through a chemical reduction step and combined with As before it will ionize. Therefore, the composition measured has been altered by the processing blank and the loading blank. It turns out that the measured composition of the spike is much more sensitive to the loading blank rather than the starting composition. The nominal compositions of the two spikes used in the determinations are given in Table 2. In both cases, the measured value of the
Table 2. Isotoplc Composttion of Enrlched Splkes

\begin{tabular}{cccccc} 
& \multicolumn{2}{c}{ Mound Laboratory } & & \multicolumn{2}{c}{ USSR } \\
\cline { 2 - 3 } \cline { 5 - 6 } nuclide & certificate & measured & & certificate & measured \\
& & & & & 0.173 \\
${ }^{32} \mathrm{~S}$ & 3.27 & 3.47 & & & 0.00535 \\
${ }^{33} \mathrm{~S}$ & 2.66 & 2.70 & & 99.999 & 99.82 \\
${ }^{34} \mathrm{~S}$ & 93.16 & 93.05 & & 99.05 & 0.00111 \\
${ }^{36} \mathrm{~S}$ & 0.92 & 0.78 & & \\
\hline
\end{tabular}
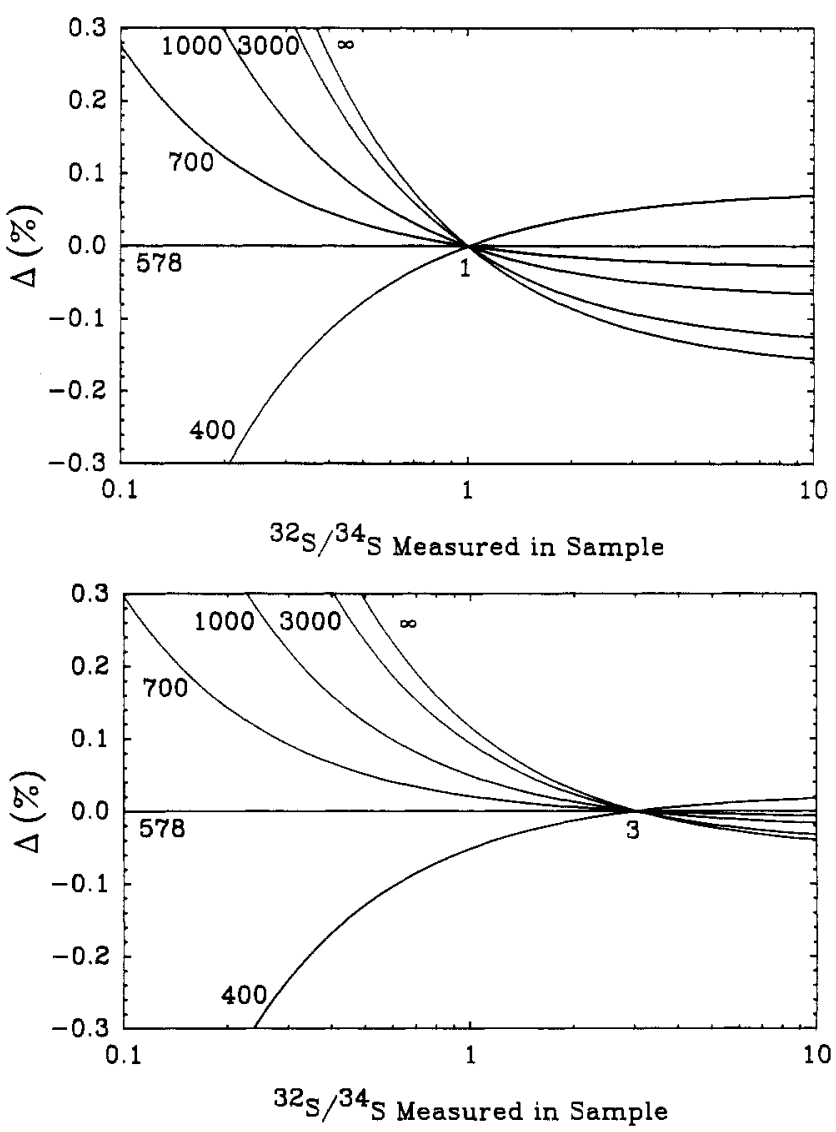

Flgure 1. Bias in relative percent in the measured sulfur concentration for different values of the true spike ratio relative to the best measured value of 578 where the splke was calibrated at a measured ratio of 1 (a, top) and 3 (b, bottom).

${ }^{32} \mathrm{~S} /{ }^{34} \mathrm{~S}$ ratio is different from that claimed by the producer. However, both columns could give the correct composition because the chemical processing of the spike may alter the ratios. The value that must be used in eq 2 is the value of the spike in the storage flask after its initial processing in a Carius tube and subsequent conversion to sulfate. Fortunately, the degree of bias resulting from lack of knowledge of the true spike composition is a well-bounded problem. The problem is illustrated using the high purity spike as an example. The largest measured ${ }^{34} \mathrm{~S} /{ }^{32} \mathrm{~S}$ ratio of the spike was 578 . The problem is bounded by the assumption of a zero loading blank, and the good assumption that the blank is lower than $2 \mathrm{ng}$. The last assumption has been inferred from loading blank experiments. This leads to a composition in the flask with a ratio between 673 and 3013 . The potential bias from this effect in an unknown sample is shown in Figure 1a,b. In these figures the bias, in percent, has been plotted as a function of the measured ratio. In Figure $1 a, b$ it has been assumed that the spike has been calibrated using ratios of 1 and 3 , respectively, and that the composition of the spike is equal to the best measured ratio, which was 578 . It is seen that if 
samples are spiked and measured at the same ratio that was used for the spike calibration, then the bias is exactly zero. However, if the samples are spiked at a value that is different from that used for the spike calibration, then there is a bias in the final result that is a nonlinear function of the ratio. In the figures, the biases for several different possible ratios of the spike have been plotted. The problem is bounded in the sense that the ${ }^{32} \mathrm{~S} /{ }^{34} \mathrm{~S}$ ratio in the spike must be less than infinity but equal to or greater than 578 , which has actually been measured. The curve for a spike ${ }^{32} \mathrm{~S} /{ }^{34} \mathrm{~S}$ ratio of 400 is shown only for comparison. These graphs show that the bias from this effect is small if samples are underspiked relative to the values used for calibration of the spike. In Figure $1 \mathrm{~b}$, it is seen that for measured ratios between 1 and 10 the bias is less than $0.1 \%$, but because of the sign change at a value of 3 , the bias between two samples could be $0.2 \%$.

Chemical Blanks. The analytical blank is the "Achilles heel" in chemical analysis. ${ }^{20}$ The analytical blank is defined, in this case, as any sulfur that is not indigenous to the sample but comes in contact with the sample, equilibrates with the sulfur spike, and is measured as if it were part of the sample. In all types of analyses, the chemical blank is frequently the fundamental limitation to accuracy and to the usable sensitivity of an analytical technique. Frequently, accurate methods produce highly biased results due to a lack of knowledge of or improper consideration of the chemical blank. Accurate chemical determinations require accurate knowledge of the chemical blanks and the chemical yields at each stage of the separation process. If the blank correction is not exact, a bias may be introduced in the final value. An accurate correction can only be made if the exact functional form of the blank correction is known and the variables measured. For the case of an internal standard where both spike, sample, and blank are lost in each successive separation step $(n)$, the true value for the analyte, $T$, is given by the following relationship:

$$
T=M+B_{\mathrm{r}}+\sum_{i=1}^{n} B_{\mathrm{s}_{i}} \prod_{j=0}^{i-1} Y_{j}^{-1}+B_{1} \prod_{j=0}^{n} Y_{j}^{-1}
$$

where $M$ is the actual measured value, $Y_{j}$ is the chemical yield between steps $n_{j}-1$ and $n_{j}$, and $B_{\mathrm{r}}, B_{\mathrm{s} ;}$, and $B_{1}$ are the reagent blank, the separation blank, and the loading blank, respectively. In such a separation process, the number of variables in the blank function increases as $2 n+4$, and the number of chemical yields that must be determined equals $n-1$. Therefore, if $n$ $\geq 2$, the amount of work required to use the exact blank function is almost insurmountable. ${ }^{13}$ In the separation procedure for sulfur, $n=1$; and therefore, eq 5 yields the following:

$$
T=M-\left[B_{\mathrm{r}}+\frac{B_{\mathrm{s}_{1}}}{Y_{0}}+\frac{B_{1}}{Y_{0} Y_{1}}\right]
$$

In this procedure, chemical blanks were determined in parallel with each set of three samples. One very important

(20) Murphy, T. J. In Accuracy in Trace Analysis: Sampling. Sample Handling. Analysis; LaFleur, P. D., Ed.; U.S. Government Printing Office: Washington, DC, 1976; pp 509-539.
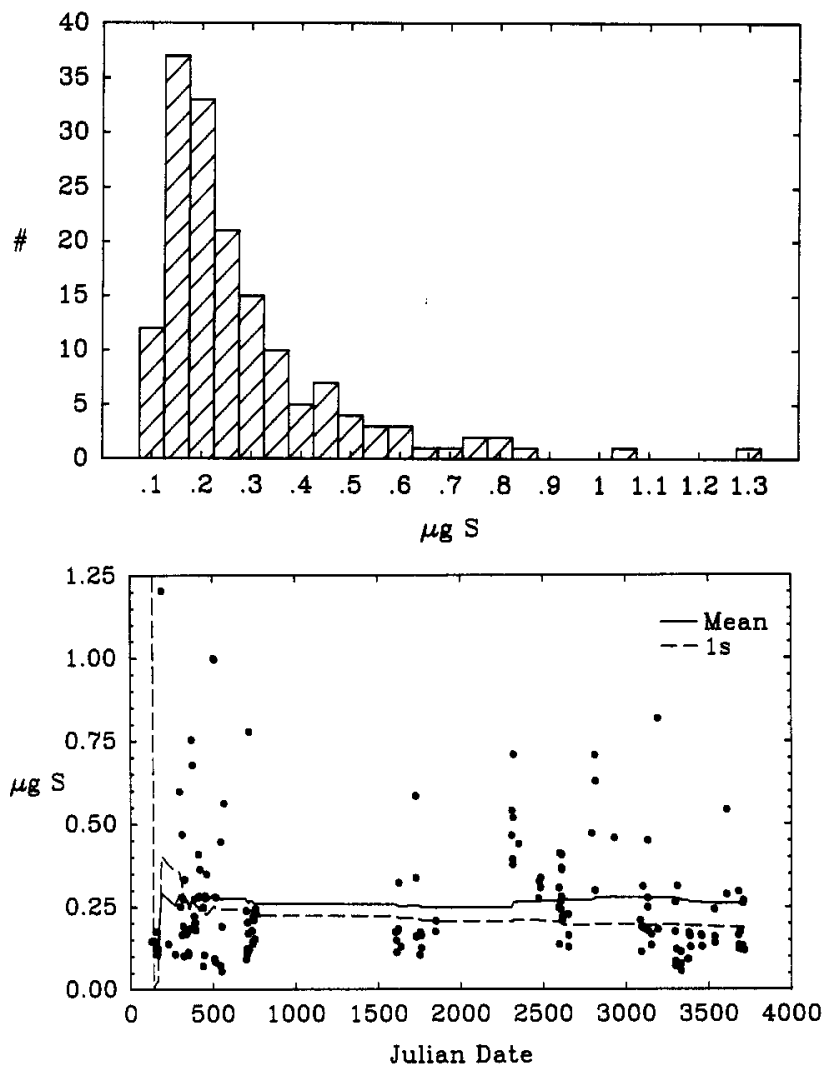

Figure 2. (a, top) Histogram of 158 sulfur blanks determined over a 10 -year period. Bin size is $0.05 \mu \mathrm{g}$ of $\mathrm{S}$. (b, bottom) A chronological plot of the 158 sulfur blanks and the running mean and standard deviation. The grand value is $0.26 \pm 0.18 \mu \mathrm{g}$ of sulfur (1s).

result of this work is that a large number of blanks have been determined over a 10-year period using the same procedure and laboratory. To date, we have determined 158 chemical blanks covering a period starting May 6, 1981, and ending March 1991. The mean value of these blanks and the standard deviation is $0.256 \pm 0.185 \mu \mathrm{g}$ of sulfur (1s). These blanks are plotted in Figure 2a,b. Figure 2a shows a histogram of 158 sulfur blanks. This histogram may be a single distribution or the sum of two or more distributions. One would expect blanks that are under statistical control to follow a distribution that is approximately log-normal.

Several statistical tests were performed on the data. A Box-Cox normality plot ${ }^{21}$ was performed where the data are transformed by the function

$$
\left(y^{\lambda}-1\right) / \lambda
$$

where $y$ is the value of the blank and $\lambda$ is an adjustable parameter. ${ }^{22}$ For $\lambda=0$, this transformation corresponds to a logarithmic distribution (from l'Hospital's rule). The correlation coefficient (CF) of unity was found for $\lambda=-0.3$; however, at $\lambda=0$, the CF was about 0.98 . A probability plot of the natural logarithm transform of the data meets the $W$ test of Shapiro and Wilk. ${ }^{23}$ In an additional test of perhaps questionable statistical rigor, the tails of the distribution were reflected about the median value and tested for log-normality,

(21) Hahn, G. J.; Shapiro, S. S. Statistical Models in Engineering; John Wiley \& Sons: New York, 1967.

(22) Box, G. E. P.; Cox, D. R. J. R. Statist. Soc. Ser. B. 1964, 26, 211

(23) Shapiro, S. S.; Wilk, M. B. Biometrika 1965, 552, 591. 
and both met the test. The exact distribution of the data is interesting, but it is difficult if not impossible to assign a specific physical interpretation to the distribution.

One important piece of information that is hidden in a histogram is the value of the blanks versus time. A more informative and useful plot of the blanks is given in Figure $2 \mathrm{~b}$ where the blanks are plotted against the Julian date with day number 1 starting with January 1, 1981. Also plotted on this graph is the cumulative mean and its standard deviation. This plot is a scatter diagram with no real structure. This figure shows that all the large blanks (>1.0 $\mu \mathrm{g}$ of $\mathrm{S})$ were observed early in the development of the procedure and probably resulted from a lack of experimental control. It would be misleading to use the grand mean and the standard deviation or worse yet the standard deviation of the mean in the correction of our sulfur measurements. At the inception of this procedure, we opted for the conservative approach and measured a blank with each set of three samples as described in the first part of the experimental section, and this blank was used to correct the sulfur values for these three samples. The uncertainty for the blank has been taken conservatively to be equal to the measured value of the blank itself.

One could argue that since the distribution of the blanks is log-normal, a log-normal statistic should be used in the blank correction which would lead to asymmetric error bars. By this procedure the mean and standard deviation are equal to $0.211_{-0.096}^{+0.175} \mu \mathrm{g}$ of sulfur. This approach might be useful if one wanted to decrease the number of blanks determined and use the current large data base to predict future blanks.

Sulfur Concentration in Fossil Fuels. The sulfur concentrations obtained by ID-TIMS measurements are shown in Table 3. This table gives the number of samples determined, the sulfur concentration, and the absolute and relative uncertainties. The assessment of homogeneity of sulfur and the concentration of sulfur was performed on individual bottles selected at random from the complete bottled lot of the SRM. For most SRMs, the homogeneity of the lot was initially checked at NIST on at least 12 different bottles by X-ray fluorescence analysis. Differences of $0.1 \%$ are resolvable by this technique. For the mass spectrometric determinations, in most cases one sample from six different bottles was analyzed for sulfur. Therefore, at least 18 individual bottles from a total lot size of about 1200 bottles are assessed for homogeneity.

Sulfur Concentration in Oils. High precision sulfur concentrations have been determined in four kerosene and nine oil SRMs ranging in sulfur concentration from $151 \mu \mathrm{g}$ $\mathrm{g}^{-1}$ to $4.2 \%$. For the ID-TIMS determinations, the total uncertainties for these liquid fuels are about $0.5 \%$, which is close to the minimum uncertainty for this procedure which is about $0.2 \%$. These small uncertainties indicate that these materials are homogeneous compared to SRM coals. Repeated analyses of SRMs 1617 and $1622 \mathrm{c}$ demonstrate the high reproducibility of this technique and indicate that these materials are stable with respect to sulfur concentration for several years.

Sulfur Concentration in Coals. Sulfur concentrations have been determined for 14 SRM coals. Coal contains both inorganic and organic sulfur. Coal with high sulfur content normally contains a large amount of inorganic sulfur in the form of the mineral pyrite $\left(\mathrm{FeS}_{2}\right)$. One would expect that the

Table 3. Summary of Results of Sulfur Concentrations in SRM Fossil Fuels

SRM

1616 , kerosene $1-\mathrm{K}$ 1617 , kerosene $2-\mathrm{K}$

$1624 a$, diesel fuel 2724 , diesel fuel

$1619 a$, fuel oil $1620 \mathrm{~b}$, residual fuel oil $1621 \mathrm{c}$, residual fuel oil $1621 \mathrm{~d}$, residual fuel oil $1622 \mathrm{c}$, residual fuel oil

$1622 \mathrm{~d}$, fuel oil

$1624 \mathrm{~b}$, diesel fuel

$1623 \mathrm{~b}$, residual fuel oil

2717 , residual fuel oil

1632a, bituminous

$1632 \mathrm{~b}$, bituminous

1635 , subbituminous

2682 , subbituminous

2682a, subbituminous

2683 , bituminous

2683a, bituminous

2683a, bituminous

2684 , bituminous

$2684 a$, bituminous

2684a, bituminous

2685 , bituminous

$2685 \mathrm{a}$, bituminous

2692, bituminous

$\begin{array}{cc}n & \begin{array}{c}\text { \% sulfur } \\ \text { (mean) }\end{array} \\ & \text { Kerosene } \\ 3 & 0.01507 \\ 3 & 0.1705 \\ 3 & 0.1704 \\ 3 & 0.14791 \\ 6 & 0.04253\end{array}$

uncertainty

(absolute)

uncertainty

$(\%)^{a}$

$\pm 0.00022$

$\pm 0.0026$

$\pm 0.0036$

$\pm 0.00081$

1.4

1.5

2.1

0.54

Oil

\subsection{8}

4.2199

1.0499

1.0109

2.0358

2.0302

2.041

2.031

0.3329

0.3479

$\pm 0.00085$

2.1

$\pm 0.0044 \quad 0.606$

$\pm 0.0056$

$\pm 0.0052$

$\pm 0.0044$

$\pm 0.0084$

$\pm 0.0068$

$\pm 0.013$

$\pm 0.012$

$\pm 0.0015$

$\pm 0.0011$

$\pm 0.014$

Con

Coal
1.592

1.592

1.897
1.892

1.892
0.354

0.494

0.494
0.4865

1.896

1.887

1.904

3.076
3.058

3.084

3.084
4.76

4.730

1.1168

\pm 0.016
\pm 0.056
\pm 0.040
\pm 0.014
\pm 0.011
\pm 0.0036
\pm 0.037
\pm 0.022
\pm 0.081
\pm 0.090
\pm 0.020
\pm 0.040
\pm 0.19
\pm 0.033
\pm 0.0074
8

${ }^{a}$ This is the total uncertainty for the determination as defined by eq 

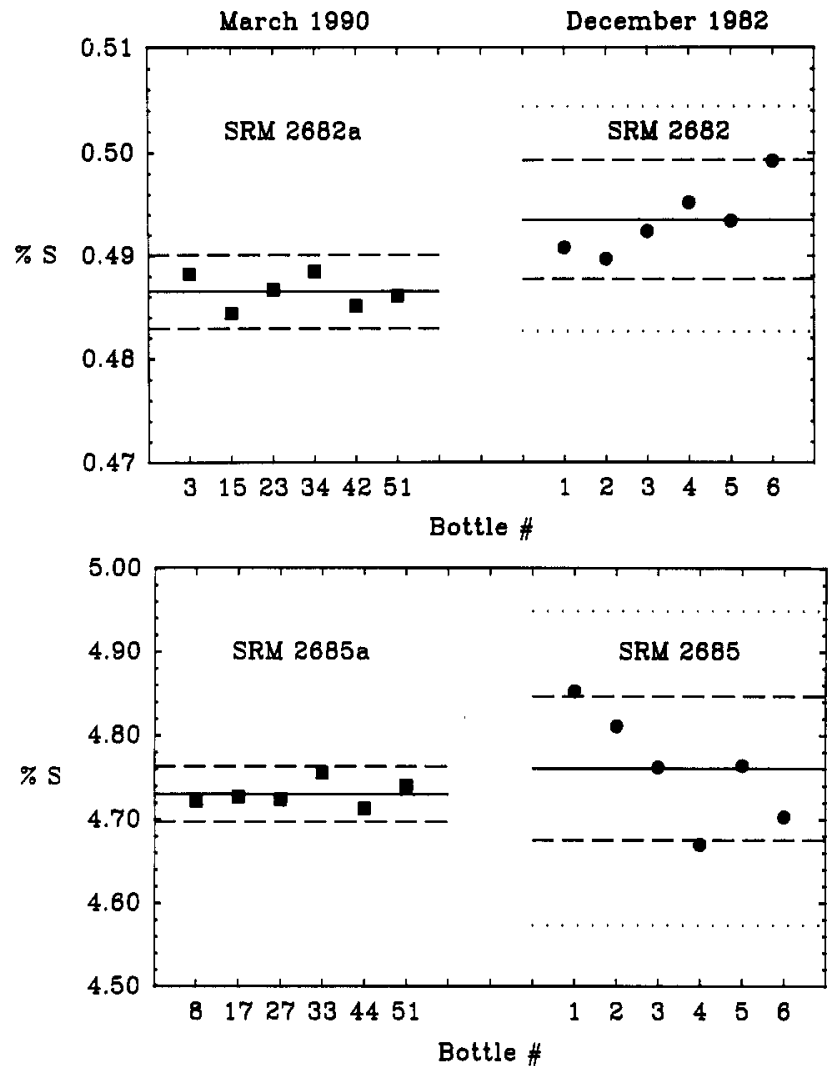

Figure 3. (a, top) Comparison of the sulfur determinations in a subbituminous and (b, bottom) bituminous coal separated in time by 7 years. The original error bars in 1982 are represented by the dotted line. The dashed error bars were computed using eq 8 in the text.

coals which were all bottled from the same parent material. The isotope dilution procedure has obtained the identical concentration for these three SRMs over a 9-year period. MacDonald ${ }^{9}$ carried out a careful study of sulfur in 2683 and claimed that the certified value was low by about $0.04 \%$ absolute, but his values agreed with the ID-TIMS values. The reason for this discrepancy is that techniques with unknown biases were included in the certification process. This is discussed in detail by Kelly et al. ${ }^{10}$

Propagation of Uncertainties. The total uncertainty given in columns 4 and 5 of Table 3, which is the $95 \%$ confidence assessment for the mean, is the sum of the uncertainties from random effects $\left(U_{\mathrm{r}}\right)$ plus the sum of the estimated uncertainties from systematic effects (biases) $\left(U_{b}\right)$. The random and systematic components were combined using the following relationship:

$\underset{\text { mean }}{\text { total uncertainty }}=U_{\mathrm{r}}+U_{\mathrm{b}}=t_{n_{1}}\left[\frac{s_{1}^{2}}{n_{1}}+\frac{s_{2}^{2}}{n_{2}}\right]^{1 / 2}+B_{1}+B_{2}+B_{3}$

for $n_{1}<n_{2}$ where $s_{1}$ is the percent relative standard deviation (\% RSD) for $n_{1}$ samples, $s_{2}$ is \% RSD for $n_{2}$ spike calibration mixes, and $t$ is Student's $t$ for $n_{1}-1$ degrees of freedom. The estimated bias consists of three parts: the blank bias for the samples, $B_{1}$; the bias in the spike calibration, $B_{2}(\sim 0.01 \%)$; and the measurement bias, $B_{3}(\sim 0.2 \%)$. For fossil fuels, the dominant terms are $s_{1}$ and $B_{3} ; B_{1}$ and $B_{2}$ are negligible compared to $B_{3}$. For oils, $s_{1}$ and $B_{3}$ are comparable in size, but for coals, $s_{1}$ is the dominant factor reflecting the inherent poorer homogeneity of this matrix. Samples are processed in groups of four: three samples and one blank. The single blank is used to make a blank correction to the three samples and to estimate the bias, $B_{1}$.

The expression of uncertainties in this paper is the result of an evolving process that sought to give a conservative but accurate estimate of the uncertainty. There is now a uniform approach at NIST for the expression of uncertainties that is contained in NIST Technical Note 1297. ${ }^{24}$ This new approach may yield uncertainties that are slightly smaller.

Certified Values. Traditionally, certified values are established using at least two independent techniques for determination of the analyte of interest, and it is required that the determinations agree. In a general sense, agreement connotes that the uncertainties for the techniques overlap. However, if the mean of these two determinations is used for the certified value, then the certified value may be a value that was not in fact measured. Although one can formulate reasonable algorithms for weighting data based on precision of the techniques, ${ }^{25}$ it is much more difficult to assign weighting on the basis of accuracy since accuracy cannot be truly assessed. Recently, SRMP has elected to certify sulfur in fossil fuels using only the single technique of ID-TIMS. Since it is assumed that a user of an SRM may only purchase one bottle of the material, the uncertainty in the certified value is given for a single bottle using the following relation:

$$
\underset{\substack{\text { total uncertainty } \\ \text { (single bottle) }}}{ }=t_{n_{1}}\left[s_{1}^{2}+\frac{s_{1}^{2}}{n_{1}}+\frac{s_{2}^{2}}{n_{2}}\right]^{1 / 2}+B_{1}+B_{2}+B_{3}
$$

which differs from relation 8 by the addition of $s_{1}^{2}$ within the brackets. This is the dominant term for the random uncertainty, and this term will be dominated by the intrinsic heterogeneity of the samples. The sample size, $n_{1}$, is usually six. The rationale for analyzing six bottles is based on a balance between analytical costs and reduction of the uncertainty achieved by having $n$ as large as possible.

Comparison with Other Techniques. A compilation and discussion of five different methods used in the certification of coals has been published by NIST. ${ }^{26}$ An exhaustive compilation of data and references on fossil fuels and other SRMs has also been published by NIST. ${ }^{27}$

The use of a high-temperature combustion technique for the determination of sulfur in coal has been evaluated by Gladney et al. ${ }^{28}$ The determinations on 10 NBS coals were within 2 standard deviations of the certified values. The uncertainties ranged from 0.4 to $3.6 \%$. It is impossible to make meaningful comparisons between the data reported here and those of other analysts whose techniques require external

(24) Taylor, B. N.; Kuyatt, C. E. Guidelines for Evaluating and Expressing the Uncertainty of NIST Measurement Results; NIST Technical Note 1297; U.S. Government Printing Office: Washington, DC, 1993, 15 pp.

(25) Paule, R. C.; Mandel, J. J. Res. Natl. Inst. Stand. Technol. 1989, $94,197$.

(26) Gills, T. E., Ed. Methods and Procedures used at the National Bureau of Standards to Certify Sulfur in Coal SRMs for Sulfur Content. Calorific Value, Ash Content; Special Publication 260-94; National Bureau of Standards: Washington, DC, 1984

(27) Gladney, W. S.; O'Malley, B. T.; Roelandts, 1; Gills, T. E., Eds. Compilation of Elemental Concentration Data for NBS Clinical, Biological, Geological, and Environmental Standard Reference Materials; Special Publication 26011: National Bureau of Standards: Washington, DC, 1987.

(28) Gladney, E. S.; Raymond, R.; Bower, N. W. Am. Lab. 1985, 17, 34. 
Table 4. Comparison of Data for Three SRMs Made from Identlcal Materlale

material

SRM 2683

SRM 2683a

SRM 1632b

SRM 2683a

SRM 1632b

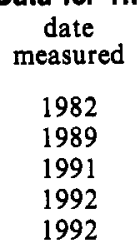

$\%$ sulfur $\pm 1 \mathrm{~s}$

$1.896 \pm 0.012$

$1.887 \pm 0.015$

$1.897 \pm 0.020$

$1.904 \pm 0.027$

$1.892 \pm 0.011$

total
uncertainty
\pm 0.037
\pm 0.022
\pm 0.056
\pm 0.081
\pm 0.040

date
certified
1983
1990
1985
1992
1985

certified

value

$1.85 \pm 0.06^{b}$

$1.89 \pm 0.03^{c}$

$1.89 \pm 0.06^{b}$

$1.89 \pm 0.03^{c, d}$

$1.89 \pm 0.06^{e}$

$a^{a}$ Columns 2-5 are results from ID-TIMS only. ${ }^{b}$ Certified value is the mean value of three techniques which included ID-TIMS. ${ }^{c}$ Certified value based on ID-TIMS determinations only. ${ }^{d}$ Sulfur was redetermined in this material, but the certified value was not changed. ${ }^{e}$ Mean of several techniques that did not include ID-TIMS.

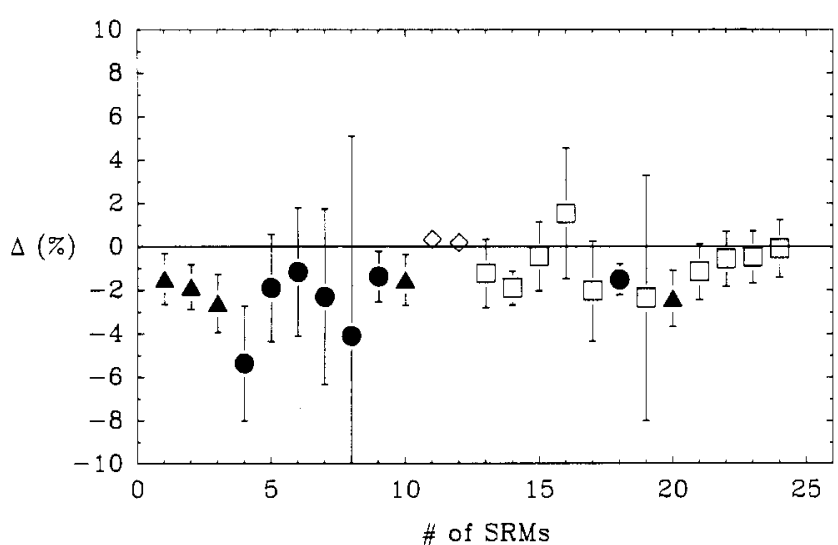

Floure 4. Comparison of sulfur values in 24 SRMs determined by IC relative to ID-TIMS listed in chronological order. The error bars are the propagated uncertainties reported for the two techniques. Solid symbols denote solld samples that must be dried; open symbols represent liquid samples. The solid trlangles represent SRMs 1577a, $1577 \mathrm{~b}, 1572$, and 1549 . Solid circles represent SRM coals 2682, 2683, $2684,2685,1635,1632 a$, and 2692 . Open squares represent simulated rainwater, SRMs 2694-I and 2694-II, which were directly injected into the IC. Open squares represent SRM oils, 1621c, 1622c (1985), 1622c (1990), 1616, 1617, 1624a, 1624b, 1620b, 1623b, and 2717.

secondary standards for calibration since the standards themselves may have biases of unknown sign and magnitude.

An IC technique with a stated precision of $5 \%$ has been used to measure sulfur in SRM coals. ${ }^{29}$ The calibration of the system was not discussed. Although the value for SRM 1635 agrees with the certified value, it is $7 \%$ lower than the value reported here. It is probably that SRM 1635 was certified low for the same reason as SRM 2683.

An IC procedure using coulometrically titrated sulfuric acid for calibration has been developed at NIST with an uncertainty of $1-3 \% .30$ The determination of sulfur in six SRM oils is reported. A comparison of published and unpublished sulfur values determined by this technique and by ID-TIMS for 24 different SRMs is plotted in Figure 4 . The sulfur concentrations ranged from $1 \mu \mathrm{g} \mathrm{g}^{-1}$ to $4.7 \%$. This figure shows deviations, expressed in percent, in IC measurements compared to ID-TIMS listed in chronological order with the different types of matrices represented by different symbols. The error bars in the figure are the propagated uncertainties for the two techniques. This figure shows that sulfur determinations by IC are almost always lower than those by ID-TIMS. However, there was close agreement between ID-TIMS and IC in two cases, represented by the open diamonds, for SRM 2694, a simulated rainwater that had the lowest concentration of sulfur of the samples plotted.

(29) Nadkarni, R. A.; Pond, D. M. Anal. Chim. Acta 1983, 146, 261.

(30) Koch, W. F. J. Chromatogr. Sci. 1989, 27, 418.
This SRM was injected directly into the IC without bomb digestion. If these two samples are excluded, the mean offset is $-1.7 \%$ with a $99 \%$ confidence interval of $\pm 0.76 \%$. This statistically significant but small offset may result from incomplete recovery in the bomb combustion as a result of incomplete combustion or physical or chemical loss of sulfur. It appears that samples that must be dried (coals and powders) are in poorer agreement than liquid samples which are used directly. In the former case, there is agreement in only four cases out of 12 , and in the latter category there is agreement in 11 cases out of 12 . Agreement is defined as the error bars overlapping the horizontal line at zero. The drying procedure is believed to be only reproducible to about $0.3 \%$ for coals. ${ }^{6,8}$

Gravimetric determinations of sulfur in coal give results that are much lower than ID-TIMS values. A comparison of gravimetric and ID-TIMS determinations of sulfur in coal are given by Kelly et al. ${ }^{10}$

Effect of Variable Isotopic Composition. Traditionally, almost all elemental concentrations are reported on a mass/ mass basis. It is important to note that although two materials might have the same concentration of sulfur on a mass/mass basis, the same mass of material might yield a different response as a result of differences in atomic weight of the sulfur contained in the two materials. This effect is small for sulfur because mass 32 is approximately $95 \%$ abundant. The same mass of sulfur from different sources will contain almost the same total number of sulfur atoms and will therefore give the same response in atomic absorption or atomic emission spectrometry. A very different response would be obtained by neutron activation of the minor isotope ${ }^{36} \mathrm{~S}$. The range in ${ }^{32} \mathrm{~S} /{ }^{34} \mathrm{~S}$ observed in this study would correspond to about a $6 \%$ spread in the ${ }^{36} \mathrm{~S} /{ }^{32} \mathrm{~S}$ ratio, which translates to a $6 \%$ difference in the ${ }^{36} \mathrm{~S}$ abundance. Therefore, sulfur measurements based on activation of the ${ }^{36} \mathrm{~S}$ nuclide could result in large but unknown bias from this effect.

\section{CONCLUSIONS}

A thorough study has been conducted on the isotope dilution thermal ionization procedure for the determination of sulfur in fossil fuels. High accuracy determinations of sulfur in 24 Standard Reference Materials have been reported. The total uncertainty $(95 \% \mathrm{CI})$ for homogeneous materials such as oils is about $0.5 \%$ and about $1-4 \%$ for coals. For coals, the uncertainty is a reflection of the heterogeneity rather than the precision of the technique.

Repeated sulfur determinations on both oil and coal samples show very good agreement demonstrating that the analytical procedures are reproducible and that the materials are stable 
for at least several years. Replication of the parent material for coal SRMs 2683, 1632b, and 2683a (see Table 4) over a 9 -year period shows very good agreement and demonstrates the long term reproducibility of the technique.

All chemical blanks determined over a 10 -year period have been presented and the data demonstrate that the blanks are under statistical control and show a distribution that is approximately log-normal. The blank corrections to the data are believed to be accurate since blanks are determined in parallel with the samples. For the determinations reported here, the blank correction is negligible relative to other sources of uncertainty.

The high accuracy and high precision of ID-TIMS for the determination of sulfur makes it an ideal single technique for the certification of sulfur in fossil fuel SRMs. The use of a single technique that is bias free for certification means that sulfur values among different SRMs should be internally consistent. Therefore, this eliminates the calibration problem when comparing two or more different determinations made by different laboratories.

\section{ACKNOWLEDGMENT}

The authors wish to acknowledge and thank T. E. Gills and W. P. Reed of the Standard Reference Material Program for their continuing support for high accuracy sulfur certification of Standard Reference Materials, W. F. Koch for permission to use unpublished data in Figure 4, and S. B. Schiller for statistical insights and inferences from the blank data. Certain commercial equipment, instruments, or materials are identified in this paper to specify adequately the experimental procedure. In no case does such identification imply recommendation or endorsement by the National Institute of Standards and Technology nor does it imply that the equipment or material is necessarily the best available for the purpose.

Received for review December 17, 1993. Accepted May 4, $1994 .{ }^{\circ}$

- Abstract published in Advance ACS Abstracts, June 15, 1994. 